\title{
Elliptically polarized frequency agile antenna on ferroelectric substrate
}

\author{
Vladimir Furlan ${ }^{1,2}$, Sebastjan Glinšek ${ }^{3}$, Tanja Pečnik, Matjaz Vidmar ${ }^{4}$, Brigita Kmet ${ }^{4}$, Barbara \\ Malič $^{4}$
}

${ }^{1}$ Slovenian Centre of Excellence for Space Sciences and Technologies, Ljubljana, Slovenia

${ }^{2}$ Taoglas GmbH, Munich, Germany

${ }^{3}$ Materials Research and Technology Department, Luxembourg Institute of Science and Technology, Belvaux, Luxembourg

4Jozef Stefan Institute, Ljubljana, Slovenia

${ }^{5}$ Faculty of Electrical Engineering, University of Ljubljana, Ljubljana, Slovenia

\begin{abstract}
A low-profile, compact and frequency-tunable antenna made on ferroelectric substrate is presented. It is designed as a planar dipole antenna with an IDC varactor integrated in the signal line. Antenna is fed through a coplanar waveguide matched to $50 \Omega$. The center frequency can be tuned from $6.895 \mathrm{GHz}$ to $7.050 \mathrm{GHz}$. It exhibits elliptical polarization and omnidirectional radiation pattern.
\end{abstract}

Keywords: Frequency-tunable antenna; ferroelectric thin films; $(\mathrm{Ba}, \mathrm{Sr}) \mathrm{TiO}_{3}$

\section{Eliptično polarizirana in frekvenčno nastavljiva antena na feroelektrični podlagi}

Izvleček: Predstavljena je frekvenčno nastavljiva planarna antena z majhnim profilom izdelana na feroelektrični podlagi. Zasnova antene temelji na planarnem dipolu z interdigitalnim varaktorjem, ki je integriran v signalni liniji. Napajana je skozi koplanarni valovod z imedanco $50 \Omega$. Resonančna frekvenca antene je prilagodljiva v območju med 6.895 GHz in 7.050 GHz. Antena ima eliptično polarizacijo in omni-smerni diagram sevanja.

Ključne besede: Frekvenčno nastavljiva antena; feroelektrične tanke plasti; $(\mathrm{Ba}, \mathrm{Sr}) \mathrm{TiO}_{3}$

*Corresponding Author's e-mail: sebastjan.glinsek@list.lu

\section{Introduction}

Nowadays Earth and space communication modules provide multiple services on different frequencies with constant demand for reduced dimensions of the communication devices. Reduced dimensions of the chassis often result in either compact antennas with narrow bandwidth or in complex multiband design. Frequency-agile antennas, on the other hand, are attractive as they are small and can at the same time seamlessly cover a wide frequency range [1, 2].

A simple way to tune antenna is to load it with varactors. In the past years thin-film ferroelectric varactors have been extensively studied for possible use in frequency-agile microwave devices [3, 4]. Lumped-element microwave circuits based on ferroelectrics are advantageous over the competing technologies, i.e., semiconductor varactors and micro-electro-mechanical systems (MEMS), in terms of space-radiation stability, reliability and their rapid response [5, 6]. High-density integrated circuits based on ferroelectric thin films with thicknesses below $1 \mu \mathrm{m}$ can be produced on a single substrate, which increases the fabrication output and reduces the cost.

This paper presents a novel antenna architecture with integrated ferroelectric varactor, which was designed to manufacture a simple yet efficient tunable antenna 
for satellite communications at frequencies between 6.875 and $7.050 \mathrm{GHz}$. In addition to tunable center frequency it is characterized also with elliptical polarization and good cosmic irradiation hardness [7]. Antenna is fed through a coplanar waveguide (CPW) loaded with an interdigital (IDC) varactor made on $\mathrm{Ba}_{0.3} \mathrm{Sr}_{0.7} \mathrm{TiO}_{3}$ thin-film substrate. Biasing of the varactor is achieved through the CPW signal line, with RF signal and bias separated with $1 \mathrm{M} \Omega$ resistor.

\section{Antenna fabrication and design}

Resonant frequency of the antenna can be effectively changed by adding a variable capacitor (varactor) at its feed point. Polycrystalline ferroelectric film, with the composition of $\mathrm{Ba}_{0.3} \mathrm{Sr}_{0.7} \mathrm{TiO}_{3^{\prime}}$, was deposited by costefficient Chemical Solution Deposition on 250 $\mu \mathrm{m}$ thick polished polycrystalline $\mathrm{Al}_{2} \mathrm{O}_{3}$ substrate (CoorsTek Inc., Golden, USA, $\varepsilon=9.9$ ). Thickness of the film was increased by several deposition-heating steps to $240 \mathrm{~nm}$ and the final annealing was performed at $900^{\circ} \mathrm{C}$ [8]. Dielectric permittivity $\varepsilon$ and losses $\tan \delta$ of the films were measured at 9.6 GHz using split-post dielectric resonators (QWED, Warsaw, Poland) and were found to be 640 and 0.02 , respectively.

Dipole antenna fed by a coplanar waveguide with integrated BST varactor was found to give the best compromise between the requirements, i.e., working frequency range, and its characteristics, i.e., dimensions and efficiency. The structure was patterned by lift-off photolithography and top $\mathrm{Cr} / \mathrm{Cu}$ electrodes with $15 \mathrm{~nm}$ of $\mathrm{Cr}$ and $2 \mu \mathrm{m}$ of Cu were deposited by DC sputtering (Balzers Sputron, Oerlikon Balzers, Liechtenstein). Its configuration is shown in Fig. 1. Width and spacing of the $50 \Omega$ CPW feed line are $1050 \mu \mathrm{m}$ and $250 \mu \mathrm{m}$, respectively. The IDC fingers are $185 \mu \mathrm{m}$ long, $10 \mu \mathrm{m}$ wide and have a $5 \mu \mathrm{m}$ gap between them. Magnified view of the 12-fingered IDC varactor is shown in the inset of Fig. 1.

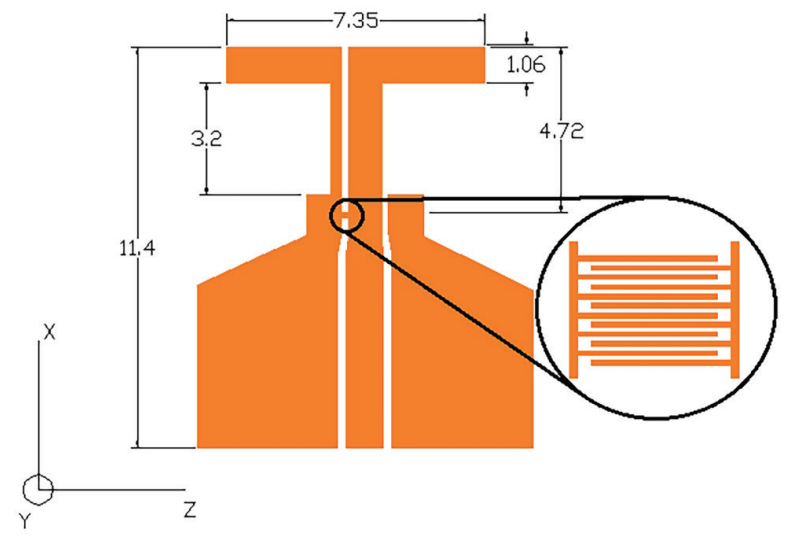

Figure 1: Configuration of the proposed tunable dipole antenna. Dimensions are given in $\mathrm{mm}$.
To facilitate the measurement, an SMA connector was mounted at the edge of the CPW. The photography of the fabricated antenna and the optical micrograph of the IDC varactor are shown in Fig. 2(a) and (b), respectively.

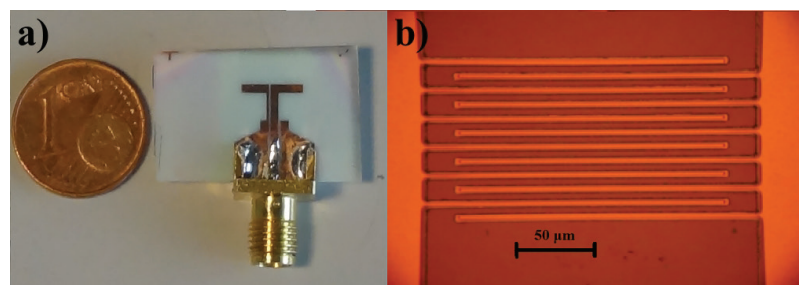

Figure 2: (a) fabricated tunable dipole antenna and (b) IDC varactor.

\section{Measurement results and comparison with existing solutions}

Return loss $S_{11}$ of the tunable dipole antenna measured at applied bias voltage up to $50 \mathrm{~V}$ is shown in Fig. 3 . The resonant frequency changes between $6.875 \mathrm{GHz}$ for $0 \mathrm{~V}$ bias and $7.050 \mathrm{GHz}$ for $50 \mathrm{~V}$ bias, which translates into tuning range of approximately $3 \%$. Higher voltages detune the antenna to the point where it is no longer viable for space communication.

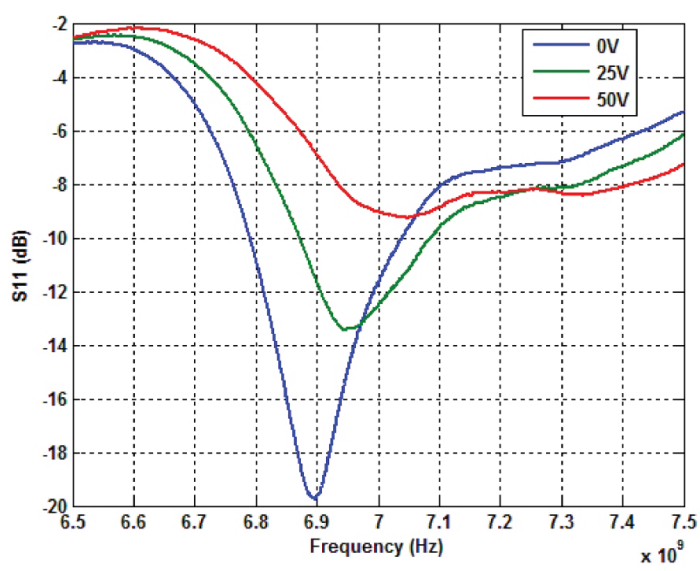

Figure 3: Measured return loss $S_{11}$ of the tunable dipole antenna.

Far-field radiation patterns were measured in the MVG Satimo StarLab (MVG Industries, Villebon-sur-Yvette, France) near field measurement chamber (Fig. 4). Currents flowing on the outside of the coaxial cable shield were suppressed as much as possible with the use of ferrite chokes, which can be seen as white cylinders near the antenna in Fig. 4. The radiation patterns at $6.875 \mathrm{GHz}$ under $0 \mathrm{~V}$ bias are presented in Fig. 5, while the Axial Ratio (AR) is shown in Fig. 6. In $X-Y$ plane antenna has an almost omnidirectional 
pattern. In the Z-X plane antenna has maximum gain in $\mathrm{X}$ axis and minimum in $\mathrm{Z}$ axis, which is typical for dipole antenna radiation pattern, although it is not perfect. It has a higher gain in $-X$ direction compared to $+X$ direction (Fig. $5 \mathrm{a}$ ) and higher gain in $\mathrm{X}$-axis compared to Y-axis. This can be explained with the current flowing on the antenna between the horizontal arms and ground plane shown in Figure 7. Maximum gain is $1.6 \mathrm{dBi}$. AR measurement shows that antenna is linearly polarized in Z-X plane but has a significantly lower AR in X-Y plane, i.e. it is elliptically polarized in $Y$ axis (Fig. 6).
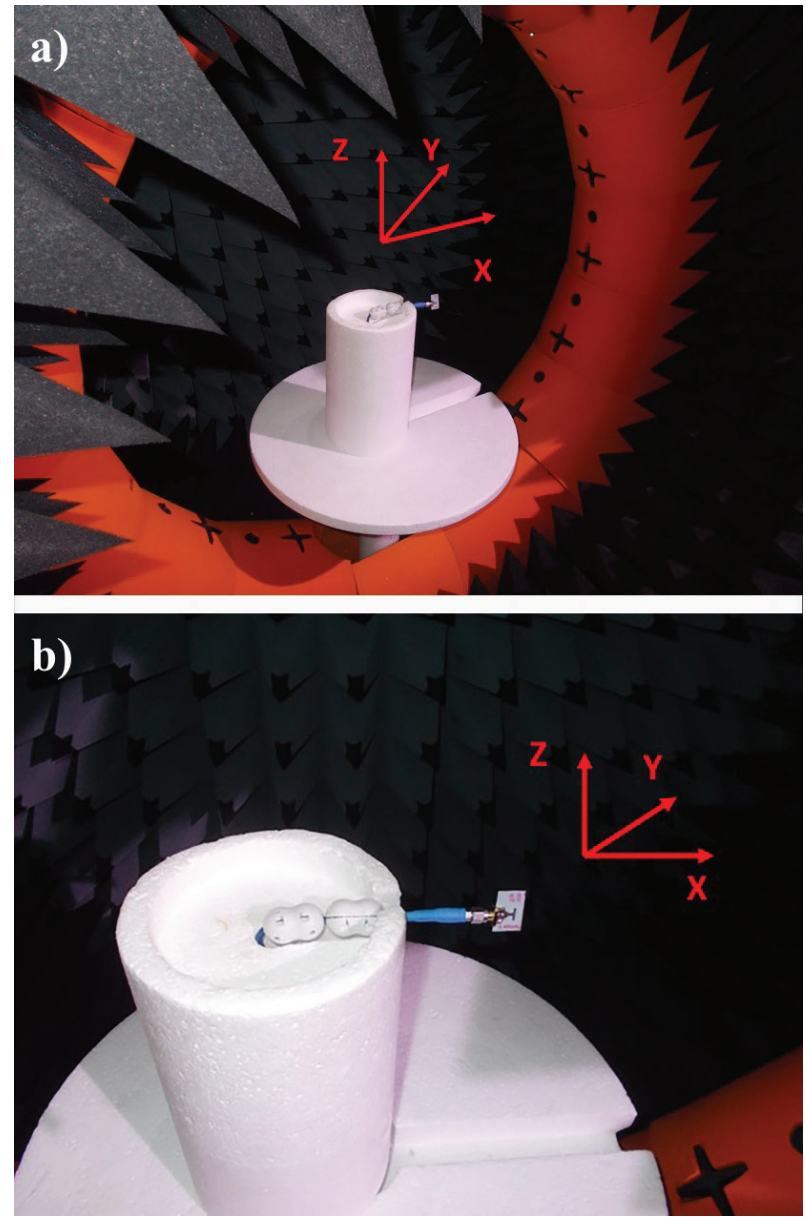

Figure 4: a) Measurement set-up for far-field radiation measurements with mounted antenna. b) Detailed view of the same set-up.

Elliptical polarization and irregular radiation pattern can be explained by examining the current distribution on the antenna, which was simulated with Sonnet Software 3D planar high-frequency electromagnetic software and is shown in Fig. 6. Vertical parts of the antenna between horizontal dipole and ground plane are electrically far apart. Consequently, currents flowing into the antenna though the signal line and out of the antenna through the ground plane do not cancel each other out. Antenna is therefore radiating not only from its horizontal parts, as could be expected for a dipole antenna, but also from its vertical parts. This induces vertical component into the radiated electromagnetic field.

Compared to the existing literature data on tunable antennas based on BST-film varactors, the $3 \%$ tuning of resonant frequency at $50 \mathrm{~V}$ exceeds the values reported for slot loop antennas, for which either $3 \%$ or $1 \%$ tuning was achieved with 200 [9] and $40 \mathrm{~V}$ bias

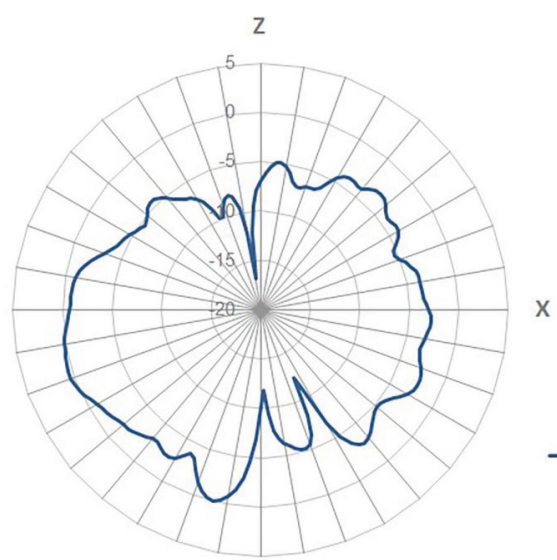

(dBi)

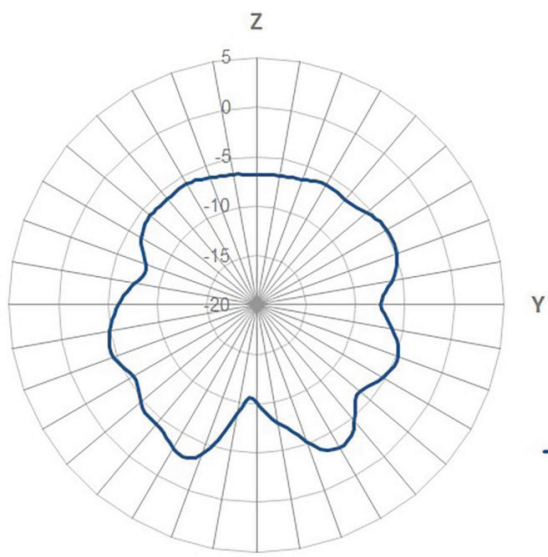

b)

(dBi)

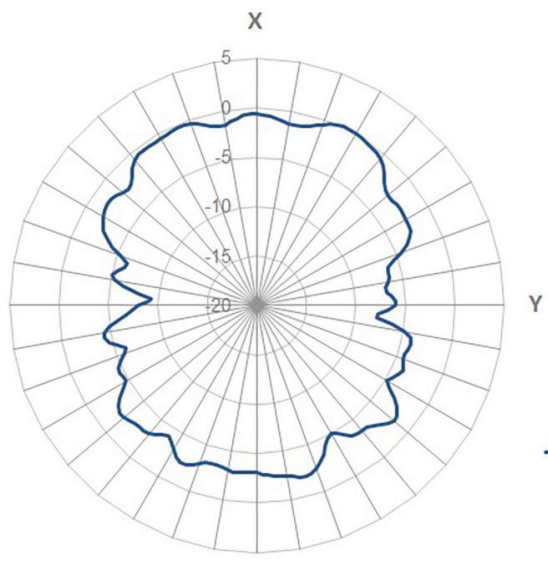

c)

(dBi)

Figure 5: 2D radiation patterns measured at $6.875 \mathrm{GHz}$. a) Z-X plane, b) Z-Y plane and c) X-Y plane. 
[10], respectively. However, it is inferior to the $8 \%$ tuning achieved with $10 \mathrm{~V}$ in Bowtie antenna with three IDC varactors integrated in the feed line [11].

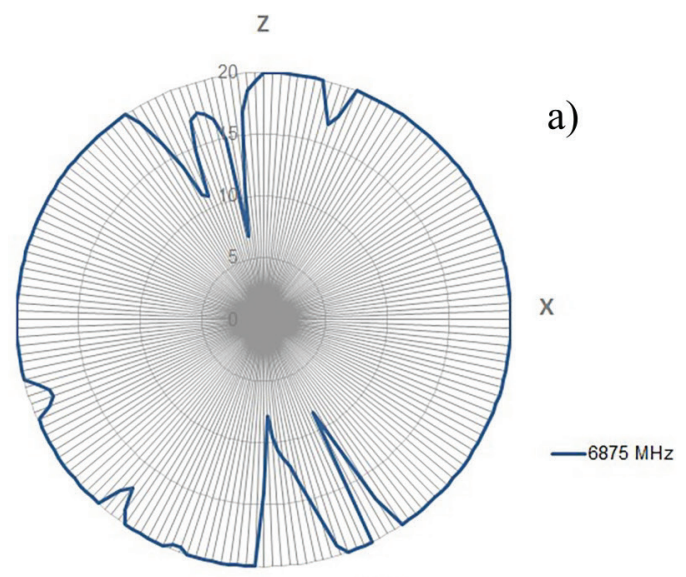

(dB)

Z

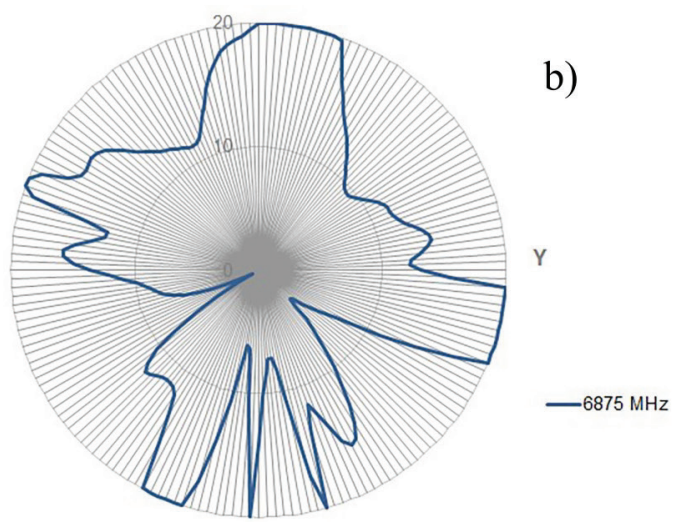

(dB)

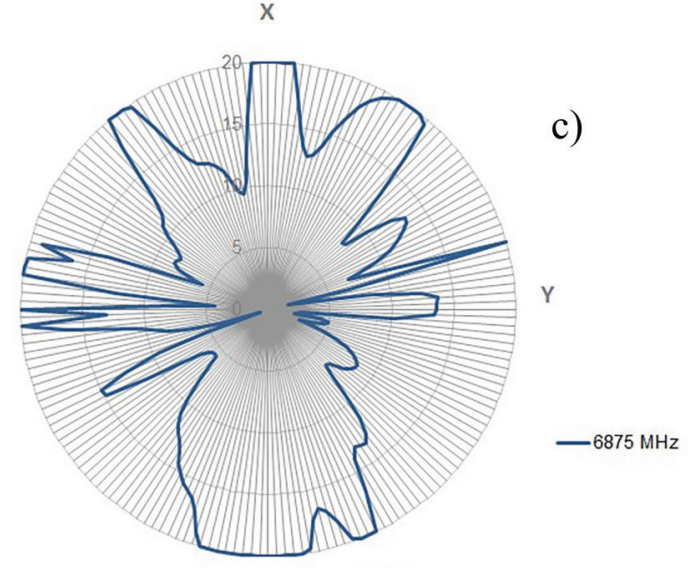

(dB)

Figure 6: Axial Ratio diagrams measured at $6.875 \mathrm{GHz}$. a) Z-X plane, b) Z-Y plane and c) X-Y plane.

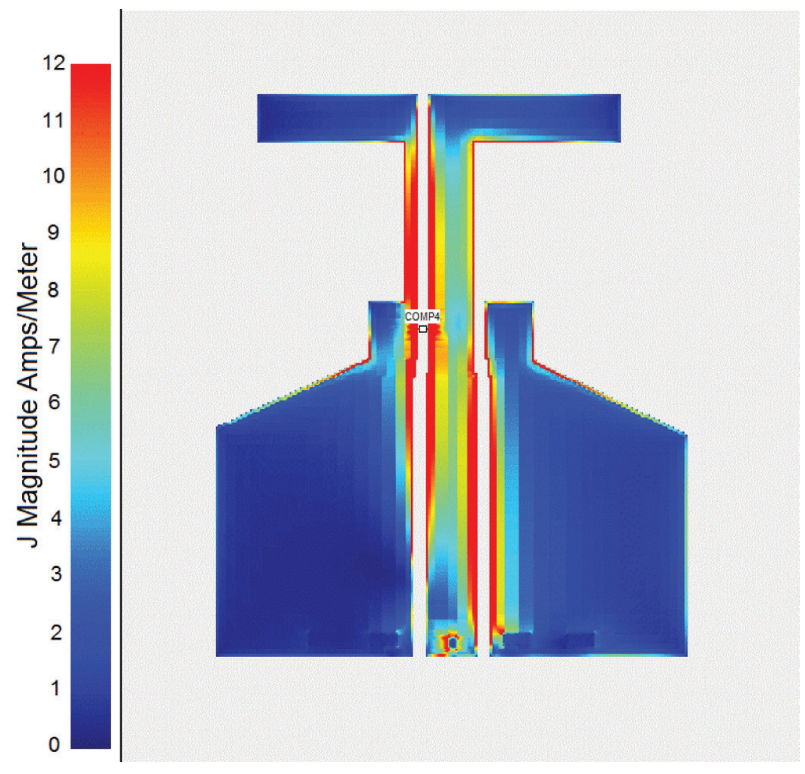

Figure 7: Tunable dipole antenna current distribution at $6.875 \mathrm{GHz}$.

\section{Summary}

A low-cost and compact frequency agile antenna on ferroelectric substrate was made and measured. An IDC varactor integrated in the antenna can shift its resonant frequency by $3 \%$ when bias voltage of $50 \mathrm{~V}$ is applied. In Y-axis antenna exhibits elliptical polarization with low axial ratio, which is desirable in Earth and satellite communication as it reduces fading of the signal. Design allows a compact, lightweight and low cost manufacturing, which is anticipated for space applications.

\section{Acknowledgments}

This work was supported by European Space Agency as part of the Ferro-Patch project and the Slovenian Research Agency (ARRS, J2-5482, P2-0105).

\section{References}

1. J. M. Carrere, R. Staraj, G. Kossiavas, "Small Frequency Agile Antennas", Electronics Letters, vol. 37, no. 12, June 2001, pp. 728-729, 2001. https://doi.org/10.1049/el:20010529

2. R. T. Cutshall, R. W. Ziolkowski, "Performance Characteristics of Planar and Three-Dimensional Versions of a Frequency-Agile Electrically Small Antenna", IEEE Antenn. Propag. M., vol. 56, no. 
6, pp. 53-71, 2014. https://doi.org/10.1109/ MAP.2014.7011020

3. Y. Zheng, A. Hristov, A. Giere, R. Jakoby, "Suppression of harmonic radiation of tunable Planar Inverted-F Antenna by ferroelectric varactor loading", IEEE MTT-S Microwave Symposium Digest, pp. 959-962, 2008. https:// doi.org/10.1109/MWSYM.2008.4632993

4. H. Jiang, M. Patterson, C. Zhang, G. Subramanyam, "Frequency tunable microstrip patch antenna using ferroelectric thin film varactor", Proceedings of the IEEE 2009 National Aerospace \& Electronics Conference, pp. 248-250, 2009. https://doi. org/10.1109/NAECON.2009.5426620

5. S. Gevorgian, "Ferroelectrics in microwave devices, circuits and systems: physics, modeling, fabrication and measurements", Springer, London, 2010.

6. R. Sayyah, T. C. Macleod, F. D. Ho, "Radiationhardened electronics and ferroelectric memory for space flight systems", Ferroelectrics, vol. 413, no. 1, pp. 170-175, 2011. https://doi.org/10.1080/ 00150193.2011.554145

7. S. Glinšek, T. Pečnik, V. Cindro, B. Kmet, B. Rožič, B. Malič, "Role of the microstructure in the neutron and gamma-ray irradiation stability of solutionderived $\mathrm{Ba}_{0.5} \mathrm{Sr}_{0.5} \mathrm{TiO}_{3}$ thin films", Acta Mater., Vol. 88, pp. 34-40, 2015. https://doi.org/10.1016/j. actamat.2015.01.028

8. T. Pečnik, S. Glinšek, B. Kmet, B. Malič, "Combined effects of thickness, grain size and residual stress on the dielectric properties of $\mathrm{Ba}_{0.5} \mathrm{Sr}_{0.5} \mathrm{TiO}_{3}$ thin films", J. Alloy. Compd., vol. 646, pp. 766-772, 2015. https://doi.org/10.1016/j.jallcom.2015.06.192

9. V. K. Palukuru, M. Komulainen, T. Tick, J. Perantie, H. Jantunen, "Low-Sintering-Temperature Ferroelectric-Thick Films: RF Properties and an Application in a Frequency-Tunable Folded Slot Antenna", IEEE Antenna and Wireless Propagation Letters, vol. 7, pp. 461-464, 2008. https://doi. org/10.1109/LAWP.2008.2001120

10. H. Y. Li, H. P. Chen, S. C. Chen, C. H. Tai, J. S. Fu, "A tunable slot loop antenna using interdigitated ferroelectric varactors", IEEE Antennas and Propagation Society Symposium, 2012. https:// doi.org/10.1109/APS.2012.6348537

11. K. C. Pan, H. Jiang, D. Brown, C. H. Zhang, M. Patterson, G. Subramanyam, "Frequency tuning of CPW bowtie antenna by ferroelectric BST thin film varactors", Proceedings of the 2011 IEEE National Aerospace and Electronics Conference, 2011. https://doi.org/10.1109/NAECON.2011.6183066 